\title{
CHANGE ANALYSIS ON SOIL EROSION OF FUJIAN PROVINCE FROM 1990 TO 2015
}

\author{
X.Q Wang ${ }^{\mathrm{a}}{ }^{*}$, S.J. Zeng ${ }^{\mathrm{a}}$, X.G. Chen ${ }^{\mathrm{a}}$, J.L. Lin ${ }^{\mathrm{b}}$, S.M. Chen ${ }^{\mathrm{b}}$
}

( ${ }^{\text {a }}$ Key Laboratory of Spatial Data Mining \& Information Sharing of Ministry of Education, Satellite Application Center of Fujian Province, Fuzhou University, Fuzhou 350116, China - wangxq@fzu.edu.cn; ${ }^{\text {b }}$ Soil and Water Conservation Experimental Station of Fujian Province, Fuzhou 350003)

KEY WORDS: Soil Erosion, Change Analysis, Spatial Pattern, Temporal Change, USLE Model, Fujian Province

\begin{abstract}
:
Soil erosion is one of major environment problems in the world, and China is one of the most serious soil erosion country. In this paper, Fujian province was used as a study area for its typical red soil region. Based on USLE model, the soil erosion modulus in 1990 and 2015 were calculated and turned to soil erosion intensity. The soil erosion distribution trend in Fujian province was decrease from south-east coastal zone to north-west inland region. In soil erosion areas, the main erosion type was light level with about $80 \%$, and the soil erosion levels above serious type were mainly sporadic distribution with less than $10 \%$. The soil erosion improved for the past 25 years. The areas of different erosion types all decreased, and the total erosion area reduced by $26.59 \%$. The improvement area mainly located in north-east, south and west region. The aggravation area mainly located in the north and some middle hilly regions. The impact of human activities is more significant for erosion control.
\end{abstract}

\section{INTRODUCTION}

Soil erosion is one of major environment problems in the world, and contributes about $85 \%$ of total global land degradation (Lin, et al, 2013). It not only breaks down land resources and gives rise to some significant environmental disasters, such as deposition, drought and flood, but also directly affects the sustainable development of regional ecological and social environments, exerting a dramatic influence on human habitat and economic development.

During the past decades, various models have been proposed to estimate soil erosion. Despite their shortcomings and limitations, the USLE (Wischmeier and Smith,1978) and RUSLE (Renard et al., 1997) are still the most frequently used equations for estimation of soil erosion. This is mainly due to the simple, robust form of the equations as well as their success in predicting the average, long-term erosion. USLE and RUSLE have been applied to various spatial scales and region sizes in different environments worldwide (Gericke, 2015; Ali and Hagos, 2016; Karamage, et al, 2016; Jiang, et al, 2016; Lin et al, 2016).

China is one of the most serious soil erosion country in the world. Red soil region is one of the four most serious regions in China, and Fujian province is one of the typical red soil regions. From 1980's, Fujian province has made great efforts to control the water and soil loss. For the past 30 years, the surface condition and the vegetation cover has changed much.

In this paper, the soil erosion of Fujian province in 1990 and 2015 were estimated based on USLE model, and the spatialtemporal change were analysed.

\section{METERIALS AND METHODOLOGY}

\subsection{Study Area and Data}

Fujian province lies in the southeast coast of China with a location of $23^{\circ} 33^{\prime}-28^{\circ} 20^{\prime} \mathrm{N}$ and $115^{\circ} 50^{\prime}-120^{\circ} 40^{\prime} \mathrm{E}$ (Figure 1). It is approximately $530 \mathrm{~km}$ long; the widest part is approximately $480 \mathrm{~km}$ and the total land area is $121400 \mathrm{~km}^{2}$. The mean elevation of Fujian is $475 \mathrm{~m}$ a.s.l. and the mean slope is around $15^{\circ}$.

It has geographical characteristics of mountain and hills as well as climatic characteristics of abundant precipitation and frequent rainstorm, which make it easy to cause soil erosion.

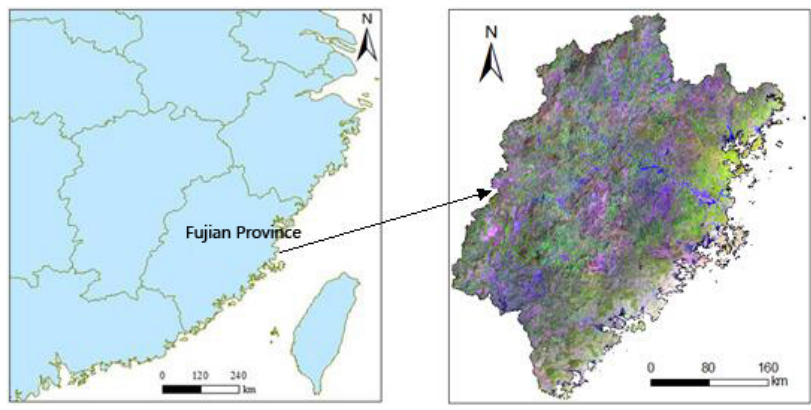

Figure 1 . The location of study area

The data used for the study included:

(1) Remote sensing data. Landsat series data, including 13 scenes of TM images acquired around 1990, and 13 scenes of OLI images acquired around 2015. The spatial resolution of TM and OLI images are $30 \mathrm{~m}$. These images were used for land use and land cover classification and fractional vegetation coverage calculation. In order to decrease the seasonal effects during images covering different areas in the same year or images covering the same area in different years, MODIS NDVI data or

* Wang, Xiaoqin, Professor, main research interests are remote sensing applications on environment and resources 
AVHRR GIMMS NDVI data were used for seasonal normalization.

(2) The DEM dataset, is the ASTER_GDEM seasonal normalization dataset with a spatial resolution of $30 \mathrm{~m}$. In general, DEM changes little. So the data were used to calculated the slope length factor and the slope steepness factor both in 1990 and 2015.

(3) Precipitation data, were acquired from 21 stations in Fujian province shared by China Meteorological Data Sharing Network, and Co-kriging interpolation was used to establish spatial distribution.

(4) Soil type coverage of Fujian Province.

\subsection{Methodology}

The USLE model was used for the estimation of soil erosion in Fujian province, which was closely related to six factors:

$$
\mathrm{A}=\mathrm{R} \cdot \mathrm{K} \cdot \mathrm{L} \cdot \mathrm{S} \cdot \mathrm{C} \cdot \mathrm{P}
$$

Where $\mathrm{A}=$ soil erosion modulus

$\mathrm{R}=$ rainfall erosivity factor

$\mathrm{K}=$ soil erodibility factor

$\mathrm{L}=$ slope length factor

$\mathrm{S}=$ slope steepness factor

$\mathrm{C}=$ cover and management factor

$\mathrm{P}=$ conservation practice factor

The flowchart is shown in Figure 2. Based on remote sensing data, soil type map, DEM and precipitation data, the six factors were estimated. After the soil erosion modulus being calculated, the changes of soil erosion were analysed.

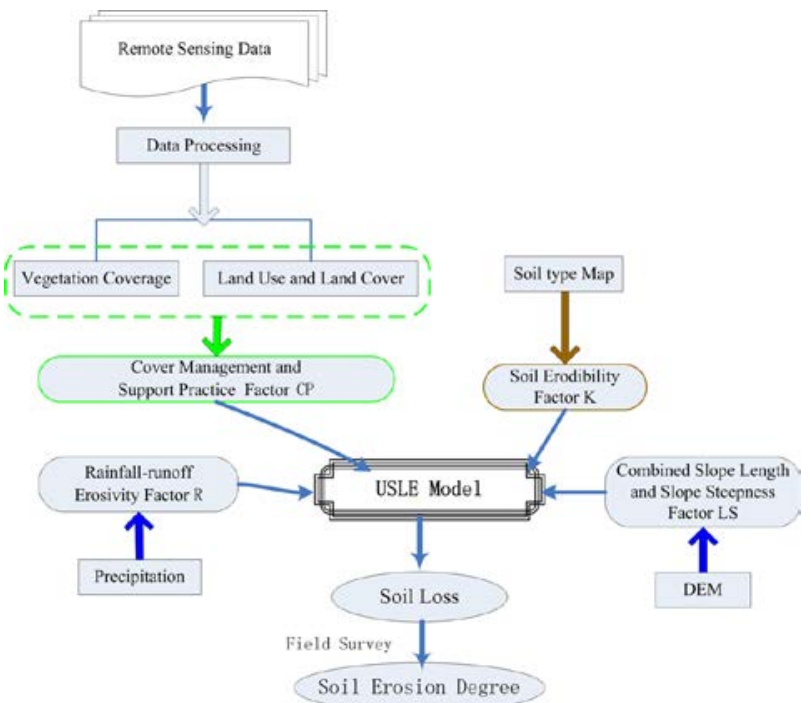

Figure 2. The flowchart for soil erosion estimation

The way to calculate the factors is of importance for the reliability of results' estimation. Formulas developed or revised for local use and parameterization methods were used in this paper, which may lead to reasonable results.

The $\mathrm{R}$ factor was calculated on a simple model (formula 2) developed by Zhou et al (1995) for the use in Fujian province, based on precipitation data.

$$
\mathrm{R}=\sum_{i=1}^{12}(-2.6398+0.3046 P i)
$$

Where $\mathrm{P}_{\mathrm{i}}(\mathrm{i}=1,2 \ldots 12)$ is the monthly precipitation.

The $\mathrm{K}$ factor was determined using soil type map and the research results from Fang and Ruan (2007), especially aim at Fujian soil types (figure 3).
$\mathrm{L}$ and $\mathrm{S}$ factors were calculated on the formulas proposed by Liu et al (2000), based on DEM data. L is calculated by the follow formulas:

$$
\mathrm{L}=(\lambda / 22.1)^{\mathrm{m}}
$$

Where $\lambda=$ slope length

$$
\mathrm{m}=\text { slope length index, is calculated by formula } 4 \text {. }
$$$$
\mathrm{m}=\mathrm{n} /(1+\mathrm{n})
$$

where $\mathrm{n}=(\sin \theta / 0.0896) /(3.0 * \sin 0.8 \theta+0.56)$,

in which $\theta=$ slope degree

$\mathrm{S}$ factor is calculated with different formulas according to the value of $\theta$ (formula 5).

$$
\left\{\begin{array}{cr}
S=10.8 \sin \theta+0.03, & \theta<5^{\circ} ; \\
S=16.8 \sin \theta-0.50, & 5^{\circ} \leq \theta<10^{\circ} ; \\
S=21.9 \sin \theta-0.96, & \theta \geq 10^{\circ} .
\end{array}\right.
$$

$\mathrm{L}$ and S factors are calculated using DEM data (figure 4).

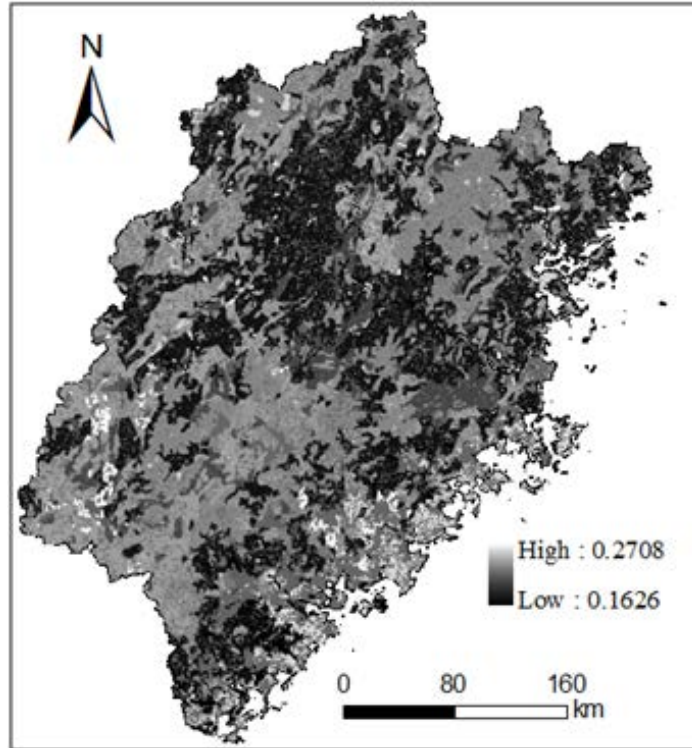

Figure 3. Spatial distribution of K factor

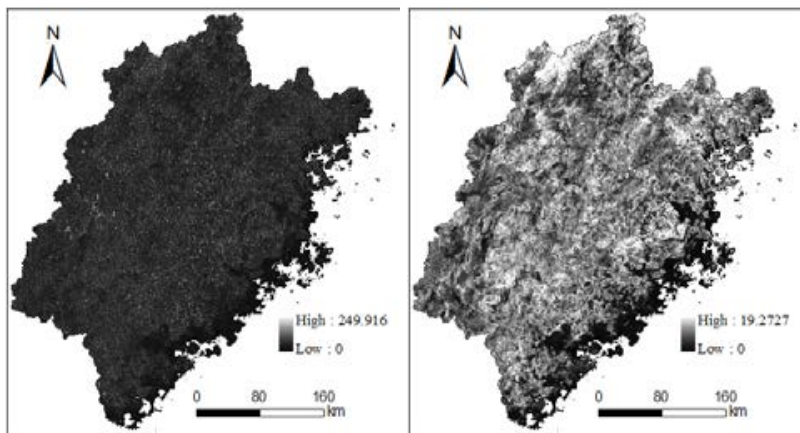

Figure 4. Spatial distribution of L and S factors

$\mathrm{P}$ factor was assigned values according to the land use/cover type classified from the Landsat TM or OLI data.

$\mathrm{C}$ factor was determined by different methods according the land use types. For vegetation cover and bare land, C factors were estimated from fractional vegetation coverage (FVC) calculated from the remote sensing data, recommend by Ma, et al (2001) (formula 6).

$$
\left\{\begin{array}{ll}
C=1 & f v c=0 \\
C=0.6508-0.3436 \cdot \lg (f v c) & 0<f v c<78.3 \\
C=0 & f v c>78.3
\end{array}\right\}
$$

When calculating FVC in large areas, a seasonal normalization method (Chen, et al, 2015) was used to eliminate the inconsistency of NDVI seasonal aspects, which using both 
low spatial high frequency data and higher spatial resolution and lower frequency data. In this paper, the former are MODIS NDVI used in 2015 and AVHRR GIMMS NDVI used in 1990, the latter are Landsat TM and OLI. TM data acquired around 1990 were all normalized to October 1990. The OLI images acquired around 2015 were all normalized to October 2015. The seasonal normalization method makes the NDVI data in large areas has comparability and consistency on the space. For other land use types, $\mathrm{C}$ factors were assigned different values ( $\mathrm{Fu}$, et al, 2006), 0 for water body and Impervious surface, 0.230 for arable land, and 0.353 for other land covers.

\section{RESULTS AND DISCUSSION}

\subsection{Change of $\mathrm{R}$ and $\mathrm{C}$ factors}

In the USLE model, $\mathrm{R}$ and $\mathrm{C}$ factors vary more rapidly and frequently than other factors. The monthly precipitation is different in different years, and the vegetation coverage also changes every year. Figure 5 shows the distribution of $\mathrm{R}$ factor in 1990 and 2015. And figure 6 shows the distribution of $\mathrm{C}$ factor in 1990 and 2015.

Despite the monthly precipitation varies much in every year, but spatial distribution of the annual precipitation changes less. So the spatial distributions of R factor in both 1990 and 2015 were similar (figure 5), which strongly depended on the annual precipitation. The $\mathrm{R}$ values decreased from the south to the north overall. The larger values lay in the southern parts. The parts with lowest values lay in the middle of the northern region.

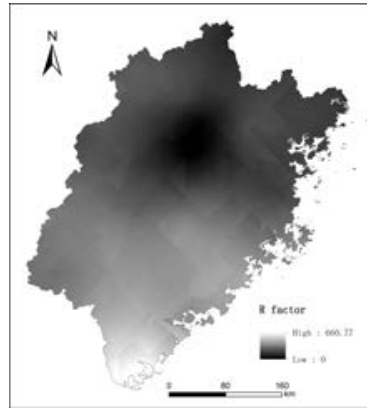

(a) 1990

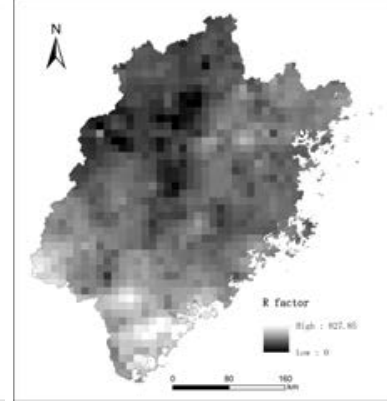

(b) 2015
Figure 5. Distribution of R factor

The spatial distributions of C factor in both 1990 and 2015 were also similar (figure 6), which strongly depended on the fractional vegetation coverage. In both years, the $C$ value presented decreasing trend from southeast coastal areas to northwest inland areas. The C value was much lower in 2015 than that in 1990. Especially in the most area of southeast coastal regions and some west regions, the $\mathrm{C}$ value is very high in 1990 . While in 2015, the C value decreased much in the southeast coastal regions and some west regions. It indicates that the vegetation coverage had improved much from 1990 to 2015.

\subsection{Analysis of soil erosion intensity}

Based on equation (1), the soil erosion modulus of Fujian province in 1990 and 2015 were calculated. According to the Soil Erosion Standard from Ministry of Water Resources (Table 1 ), the soil erosion modulus obtained were categorized into 6 erosion types (Figure 7), which is slight, light, moderate, serious, extreme and severe. Slight level means that the erosion may be ignored. The results of 2015 were verified by the field survey, and results of 1990 was compared to the results of Chen et al (2011). Both results in 2015 and 1990 were satisfactory. 3.2.1 Spatial patterns

The soil erosion was widely distributed in Fujian province, and its distribution trend was decrease from south-east coastal zone to north-west inland region (Figure 7). The dominant soil erosion regions mainly located in the west and south-east, in which Quanzhou and Zhangzhou was the most serious and the erosion area percentage was bigger than those of other regions. The erosion areas in north and middle were much less.

The main soil erosion type was light type, and the area percentage was about $80 \%$ in the erosion area. The soil erosion levels above serious type (including serious, extreme and severe types) were mainly sporadic distribution, whose area percentage was less than $10 \%$ in the erosion area.

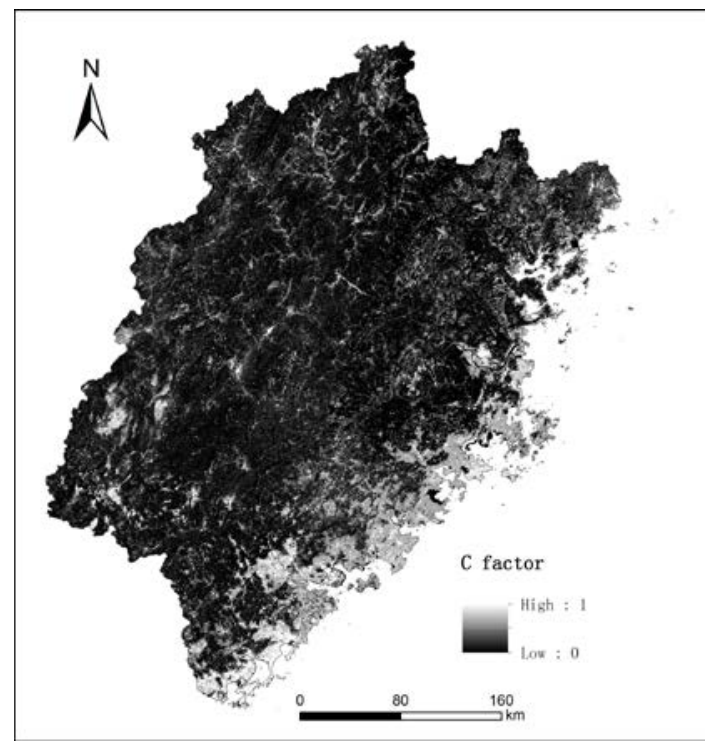
(a) 1990

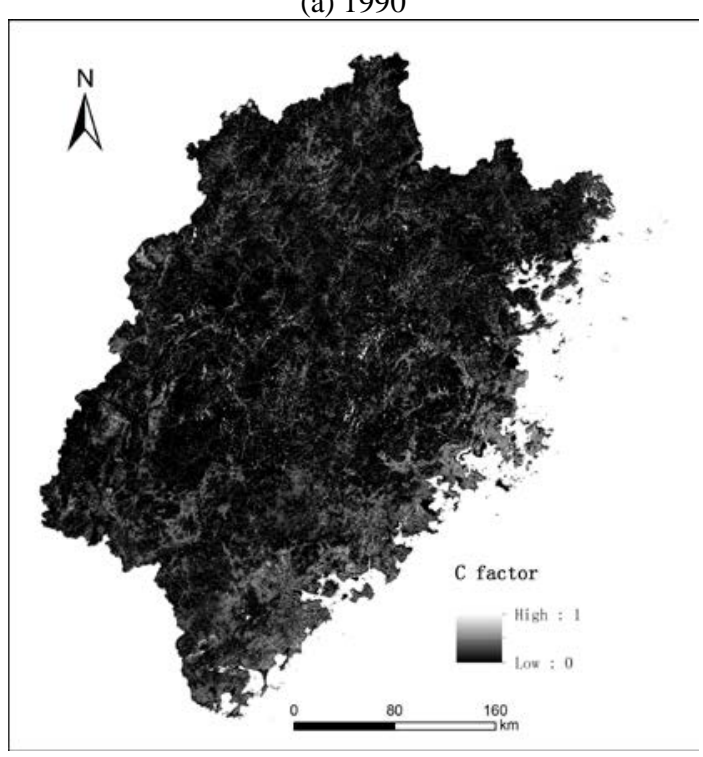

(b) 2015

Figure 6. Distribution of $\mathrm{C}$ factor

\begin{tabular}{cc}
\hline Erosion Types & $\begin{array}{c}\text { Soil Erosion Modulus } \\
\left(\mathrm{t} / \mathrm{km}^{2} \cdot \mathrm{a}\right)\end{array}$ \\
\hline Slight & $<500$ \\
Light & $500-2500$ \\
Moderate & $2500-5000$
\end{tabular}


Serious

$5000-8000$

Extreme

$8000-15000$

Severe

$>15000$

Table 1 Soil erosion types standard for red soil regions

The spatial distribution of the erosion intensity changes from 1990 to 2015 was shown in figure 8. Overall, the soil erosion improved for the past 25 years. The improvement area mainly located in north-east region, south region and west region, which were highly consistent with the regions of vegetation improvement. The aggravation area mainly located in the north region, and some middle hilly regions.
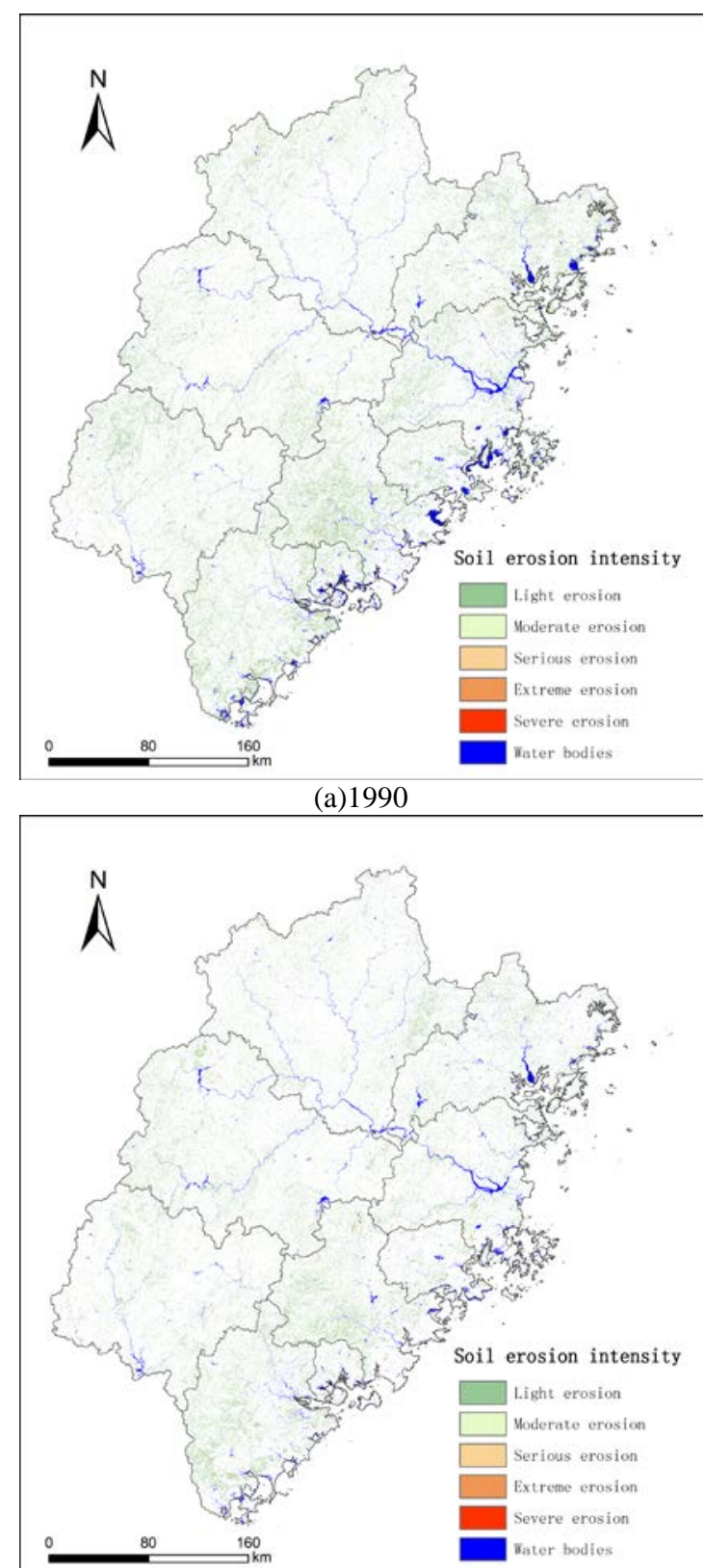

(b) 2015

Figure 7. The distribution of soil erosion types

\subsubsection{Dynamic Changes}

The statics of different soil erosion types were list in table 2, where erosion rates (ER) were the ratios of the total erosion area (EA) and the provincial area (PA) (Formula 7).

\section{$\mathrm{ER}=\mathrm{EA} / \mathrm{PA} * 100 \%$}

In the same year, the areas of different erosion types decreased sharply from light to severe. The erosion area of light type was about 7.5 times of that of moderate type, the erosion area of moderate type was about 3.1 times of that of serious type, the erosion area of serious type was about 1.8 times of that of extreme type, and the erosion area of extreme type was about 1.9 times of that of severe type. The area ratio between light type and severe type was about 75 .

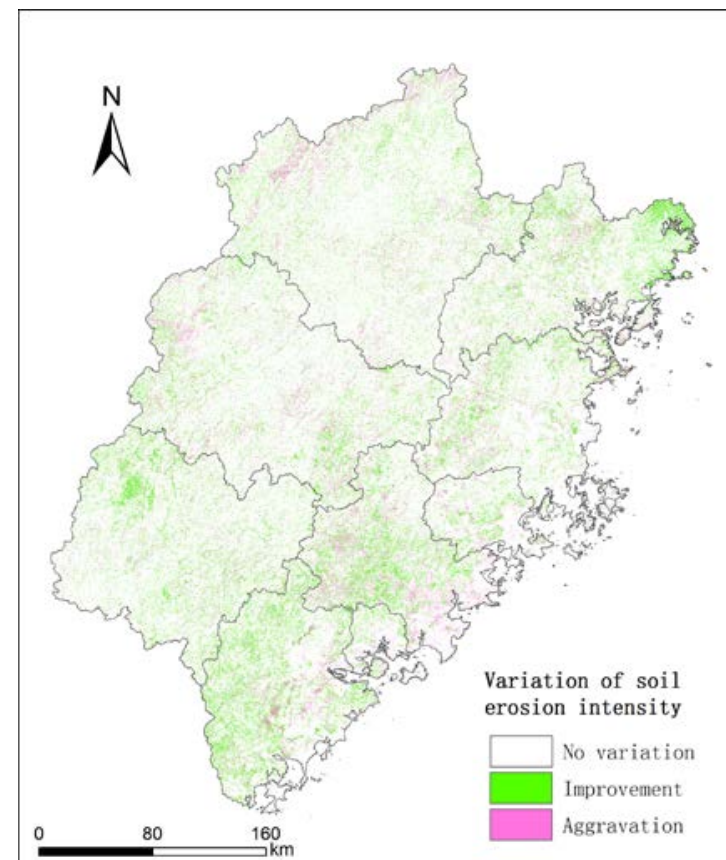

Figure 8. Spatial distribution of erosion intensity change

\begin{tabular}{ccrrr}
\hline & Types & \multicolumn{1}{c}{1990} & \multicolumn{1}{c}{2015} & $1990-2015$ \\
\hline & Light & 11787.51 & 8729.04 & -3058.47 \\
Erosion & Moderate & 1648.99 & 1123.02 & -525.97 \\
Area & Serious & 510.51 & 374.01 & -136.50 \\
$\left(\mathrm{~km}^{2}\right)$ & Extreme & 291.43 & 217.73 & -73.70 \\
& Severe & 150.07 & 119.11 & -30.96 \\
& Sum & 14388.51 & 10562.91 & -3825.60 \\
\hline \multicolumn{2}{c}{ Erosion Rate (\%) } & 11.85 & 8.70 & -3.15 \\
\hline
\end{tabular}

Table 2 the Statics of Soil Erosion Types

The percentage of different erosion types was shown in figure 9. The area percentage of light type was about $80 \%$, the area percentage of moderate type was about $10 \%$. The area percentages of serious type, extreme type and severe type were about $3.5 \%, 2 \%$ and $1 \%$ respectively.

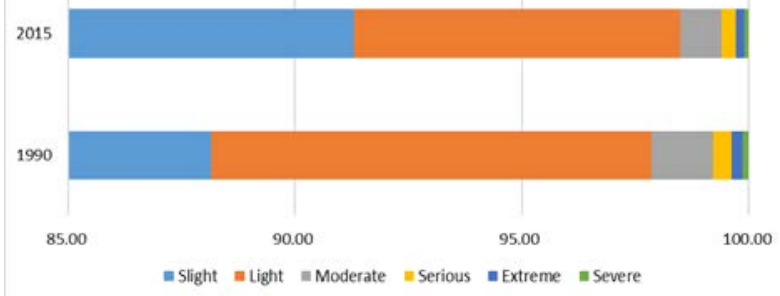

Figure 9. The percentage of different erosion types 
From 1990 to 2015, the total erosion area decreased from $14388.51 \mathrm{~km}^{2}$ to $10562.91 \mathrm{~km}^{2}$, reducing by $26.59 \%$. The erosion rate decreased from $11.85 \%$ to $8.70 \%$. The areas of different erosion types all decreased from tens to thousands square kilometres (Table 2). But the reduction percentages of different erosion types changed less, from $20-32 \%$ (Table 3 ).

The areas of different types all reduced by above $20 \%$, the annually average reduction rate was about $1 \%$. The biggest reduction with $32 \%$ was moderate type, the lowest reduction with $20 \%$ was severe type, while the other three erosion types were about $25 \%$.

\begin{tabular}{ccc}
\hline Types & Total & Annually average \\
\hline Light & -25.95 & -1.04 \\
Moderate & -31.90 & -1.28 \\
Serious & -26.74 & -1.07 \\
Extreme & -25.29 & -1.01 \\
Severe & -20.63 & -0.83 \\
Sum & -26.59 & -1.06 \\
\hline \multicolumn{2}{l}{ Table 3 Reduction rate (\%) of different erosion types }
\end{tabular}

\subsection{Driving forces}

The spatial-temporal changes of soil erosion in Fujian province were the interactional result of natural and social factors. The impact of the natural factors like soil, topography and climate is very slow. The impact of human factors like the rapid economic development and soil erosion control activities are more significant.

From 1990, the economic has developed rapidly. The GDP per capita went up from 1763 Yuan in 1990 to 67966 Yuan in 2015 Yuan. Due to the pursuit of short-term economic benefits, construction and development projects increased, such as road construction, mining, reclamation orchards and tea plantations. The excessive development causes the unreasonable land use or excessive land exploitation and leads to more serious soil erosion in some regions.

On the other hand, the Fujian government has been aware of the importance of environmental protection, and has actively made great efforts to control soil erosion. The soil erosion improved obviously for the past 25 years by afforestation, adjusting the planting structure, and so on.

\section{CONCLUSION}

USLE model was used to estimate the soil erosion of Fujian province in 1990 and 2015.

(1) The soil erosion was widely distributed and its distribution trend was decrease from south-east coastal zone to north-west inland region.

(2) The main soil erosion type was light type with about $80 \%$ in the erosion area, while the area percentage of soil erosion levels above serious type was less than $10 \%$ in the erosion area.

(3) The soil erosion obviously improved from 1990 to 2015, and the erosion area reduced by $26.59 \%$. The areas of different erosion types all decreased.

(4) Human activities played a more important role for the spatial-temporal changes of soil erosion.

\section{ACKNOWLEDGEMENTS}

The research has been supported by the National Science \& Technology Support Program (2013BAC08B01), Technology Research and Development Program of Fujian Province (2017Y4010).

\section{REFERENCES}

Ali S A, Hagos H., 2016. Estimation of soil erosion using USLE and GIS in Awassa Catchment, Rift valley, Central Ethiopia. Geoderma Regional, 7, pp159-166.

Chen, X.G., Wang, X.Q., Chen, Y.Z., 2015. Seasonal normalization processing methods of TM NDVI images in large areas. Remote Sensing Information, 30, pp81-88. (in Chinese)

Chen, Z.Q., Chen, Z.B., Chen, M.H., 2011. Geostatistical Analysis on Soil and Water Loss in Fujian Province. Journal of Natural Resource, 26, pp1394-1400. (in Chinese)

Fang G.Q. and Ruan F.S., 1997. Soil erodibility factor characters in Fujian province. Subtropical Soil and Water Conservation, pp19-23. (in Chinese)

Fu G, Chen S, Mccool D K., 2006. Modelling the impacts of no-till practice on soil erosion and sediment yield with RUSLE, SEDD, and ArcView GIS. Soil \& Tillage Research, 85, pp3849.

Gericke A., 2015. Soil loss estimation and empirical relationships for sediment delivery ratios of European river catchments. International Journal of River Basin Management, 13, pp179-202.

Jiang C, Wang F, Zhang H, et al. 2016. Quantifying changes in multiple ecosystem services during 2000-2012 on the Loess Plateau, China, as a result of climate variability and ecological restoration. Ecological Engineering, 97, pp258-271.

Karamage F, Zhang C, Kayiranga A, et al. 2016. USLE-Based Assessment of Soil Erosion by Water in the Nyabarongo River Catchment, Rwanda. International Journal of Environmental Research \& Public Health, 13, pp835-850.

Lin B S, Thomas K, Chen C K, et al., 2016. Evaluation of soil erosion risk for watershed management in Shenmu watershed, central Taiwan using USLE model parameters. Paddy and Water Environment, 14, pp1-25.

Lin, C., Zhou, S.L. and Wu, S.H., 2013. Using hyperspectral reflectance to detect different soil erosion status in the Subtropical Hilly Region of Southern China: a case study of Changting, Fujian Province. Environment Earth Science, 70, pp.1661-1670

Liu B.Y., Nearing M.A., Shi P.J., 2000. Slope length effects on soil loss for sleep slopes. Soil Society of America Journal, 64, pp.1759-1763.

Ma, C.F., Ma, J.W., Buhe-Acsaier, 2001. Quantitative Assessment of Vegetation Coverage Factor in USLE Model Using Remote Sensing Data. Bulletin of Soil and Water Conservation, 21, pp6-9. (in Chinese)

Renard, K.G., Foster, G.R., Weesies, G.A., McCool, D.K., Yoder, D.C.,1997. Predicting soil erosion by water: a guide to conservation planning with the Revised Universal Soil Loss Equation. Agricultural Handbook, vol. 703. U.S. Department of Agriculture 404 pp.

Wischmeier, W.H., Smith, D.D., 1978. Predicting rainfallerosion losses: a guide to conservation planning. Agricultural Handbook, vol. 537. U.S.Department of Agriculture. 
Zhou, F.J., Chen, M.H., Lin, F.X., 1995. The rainfall erosivity index in Fujian Province. Journal of soil and water conservation, (1):13-18. (In Chinese) 